\title{
Comparison of anthro-metabolic indicators for predicting the risk of metabolic syndrome in the elderly population: Bushehr Elderly Health (BEH) program
}

\author{
Neda Rabiei ${ }^{1} \cdot$ Ramin Heshmat $^{1} \cdot$ Safoora Gharibzadeh ${ }^{2}$. Afshin Ostovar ${ }^{3} \cdot$ Vahid Maleki $^{4,5} \cdot$ Mehdi Sadeghian $^{6}$. \\ Saba Maleki Birjandi ${ }^{1} \cdot$ Iraj Nabipour $^{7} \cdot$ Gita Shafiee $^{1} \cdot$ Bagher Larijani $^{1,8}$
}

Received: 23 June 2021 / Accepted: 15 August 2021

C) Springer Nature Switzerland AG 2021

\begin{abstract}
Background Metabolic syndrome (MetS) is a cluster metabolic disorder that includes central obesity, insulin resistance, hypertension, and dyslipidemia, and is highly associated with an increased risk of developing non-communicable diseases (NCDs). This study aimed to compare the reliability of anthro-metabolic indices [visceral adiposity index (VAI), body roundness index (BRI), and a body shape index (BSI), body adiposity index (BAI), lipid accumulation product (LAP), waist to hip ratio, and waist to height ratio] in predicting MetS in Iranian older people.

Methods This cross-sectional study was conducted based on the data of 2426 adults aged $\geq 60$ years that participated in the second stage of the Bushehr Elderly Health (BEH) program, a population-based prospective cohort study being conducted in Bushehr, Iran. MetS was defined based on the revised National Cholesterol Education Program Adult Treatment Panel III (NCEP-ATP III) criteria. The receiver operating characteristic (ROC) curve analysis was used to assess predictive performance of anthro-metabolic indices and determine optimal cutoff values. Logistic regression analysis was applied to determine the associations between MetS and indices.

Results 2426 subjects ( $48.1 \%$ men) with mean \pm SD age of $69.34 \pm 6.40$ years were included in the study. According to ATP III criteria, $34.8 \%$ of men and $65.2 \%$ of women had MetS $(\mathrm{P}<0.001)$. Of the seven examined indices, the AUCs of VAI and LAP in both genders were higher than AUCs of other anthro-metabolic indices. Also, in general population, VAI and LAP had the greatest predictive power for MetS with AUC 0.87(0.86-0.89) and 0.87(0.85-0.88), respectively. The lowest AUC in total population belonged to BSI with the area under the curve of $0.60(0.58-0.62)$. After adjusting for potential confounders (e.g. age, sex, education, physical activity, current smoking) in the logistic regression model, the highest OR in the total population was observed for VAI and LAP, which was 16.63 (13.31-20.79) and $12.56(10.23-15.43)$ respectively. The lowest OR for MetS was 1.93(1.61-2.30) for BSI.

Conclusion This study indicated that both VAI and LAP are the most valuable indices among the anthro-metabolic indices to identify MetS among the elderly in both genders. So, they could be used as proper assessment tools for MetS in clinical practice. However, the cost-benefit of these indices compared to the ATP III criteria need further studies.
\end{abstract}

Keywords Metabolic syndrome $\cdot$ Anthro-metabolic indices $\cdot$ Older adults $\cdot$ Prediction value

Gita Shafiee

gshafiee.endocrine@gmail.com

Bagher Larijani emrc@tums.ac.ir

Extended author information available on the last page of the article

\section{Introduction}

Metabolic syndrome (MetS) variously known also as "syndrome X, insulin resistance syndrome, Reaven syndrome, and the deadly quartet" is a cluster metabolic disorder that includes central obesity, insulin resistance, hypertension, and dyslipidemia, and is powerfully associated with an increased risk of developing non-communicable diseases (NCDs) such as type 2 diabetes, cardiovascular disease (CVD), nonalcoholic fatty liver disease, and stroke [1-3]. 
A systematic review and meta-analysis showed that the prevalence of MetS according to Adult Treatment Panel-III (ATP-III) / National Cholesterol Education Program (NCEP) criteria is $23.8 \%$ for $>18$ adults in Iran [4]. furthermore, in a cohort study the prevalence of metabolic syndrome based on the definition of ATP III/ NCEP was estimated to be approximately $33.82 \%$ in the Iranian elderly [5].

Obesity as an independent risk factor for metabolic syndrome, results from an imbalance in energy intake and consumption, which is manifested by the accumulation of excess fat in the body [6]. Besides the advantages and disadvantages of anthropometric indices, these indices are used as low-cost and affordable methods to assess body fat mass, obesity and predict metabolic syndrome [7]. Body mass index (BMI) or cutlet index is the most common index which is used in assessing the weight to height ratio [8]. It is noteworthy that interpretation of BMI in people with a height less than $150 \mathrm{~cm}$ should be done carefully [9]. In risk assessment, waist circumference (WC) and waist-to-hip ratio (WHR) measurements are used to assess abdominal or central obesity which is considered as a complement to BMI $[10,11]$. The waist-to-height ratio (WHtR) indicates the distribution of adipose tissue, and compared to BMI it is a better indicator of abdominal obesity, and also higher WHtR values are associated with a higher risk of metabolic syndrome [12]. Body shape index (BSI),independent of $\mathrm{BMI}$, is defined based on waist circumference, height, and weight [13], and also better than BMI, could predict premature death and the onset of metabolic syndrome [14, 15]. Body roundness index (BRI) is a new anthropometric index that is calculated based on waist circumference and height which is developed to predict both visceral body fat $[14,16]$.

The newly defined lipid accumulation product (LAP) index is a measure of central fat accumulation. It predicts the risk of metabolic syndrome, and different studies have shown that compared to BMI, LAP is a better index for predicting type 2 diabetes and CVD [17, 18]. visceral fat index (VAI) is another novel indicator, which is defined based on a combination of WC, BMI, triglycerides, and High-density lipoprotein- cholesterol (HDL-C) measurements, for men and women separately [19]. Body adiposity index (BAI) is a new surrogate measure of body fat and more accurately could predict the onset of CVD and metabolic syndrome than BMI [20, 21].

Numerous studies have shown that each of the current and new anthropometric indices has reported contradictory results for predicting metabolic syndrome and some differences in cut points among different ethnicities [22-26]. Accordingly, considering the importance of determining the cut-off point of anthropometric indices to predict the risk of metabolic syndrome, this study aims to identify the optimal cut-off points for by VAI, BRI, BAI, LAP, and BSI indices and compare and evaluate the accuracy and relevance of these indices for MetS risk prediction is performed in the elderly population.

\section{Materials and methods}

\section{Study population}

Current study is a cross-sectional study based on the second stage of the BEH program. In brief, The BEH (Bushehr Elderly Health) program is a population-based prospective cohort study being performed in Bushehr, a southern province in Iran [27]. In short, using a multistage, stratified cluster sampling method an overall of 3000 persons aged $\geq 60$ years were recruited. In the second stage of the BEH program, 2426 participants were included to investigate musculoskeletal health [28]. The study protocol was reviewed and approved by the Research Ethics Committee of both Bushehr University of Medical Sciences and Endocrinology and Metabolism Research Institute and also ethics committee of Tehran University of Medical Sciences. All study participants completed written informed consent before the study.

\section{Data collection}

Data were collected through comprehensive questionnaires including sociodemographic characteristics, general health, medical history, and lifestyle data during an interview that was performed by a trained interviewer. A fixed stadiometer and a digital scale were used for the measurements of height and weight, respectively. Waist circumference (WC) was measured at a point midway between the iliac crest and the lowest rib in the standing position crest and the hip circumference was measured at the widest part of the hips. Body mass index (BMI) was calculated by the formula weight $(\mathrm{kg})$ / [height $\left(\mathrm{m}^{2}\right)$ ]. Blood pressure (BP) was measured twice by a standard mercury sphygmomanometer after $15 \mathrm{~min}$ of rest in the seated position and then the mean of the two measurements was considered as the participant's systolic and diastolic blood pressures. The physical activity level was evaluated by a standard questionnaire based on metabolic equivalent (MET) levels [29].

Patients' lipid profile and blood glucose were measured by assessing venous samples, drawn after overnight fasting. Using the enzymatic colorimetric method with cholesterol esterase and cholesterol oxidase, total cholesterol (TC) was determined. Details for the measurements of fasting blood glucose (FBG), high-density lipoprotein (HDL-C), low-density lipoprotein cholesterol (LDL-C), and triglyceride (TG) were reported elsewhere [28]. 


\section{Definition of variables}

MetS was defined based on the revised National Cholesterol Education Program Adult Treatment Panel III (NCEP-ATP III) criteria by the presence of three or more of the following criteria: abdominal obesity [WC $>102 \mathrm{~cm}$ (men) or $>88 \mathrm{~cm}$ (women)]; TG $\geq 150 \mathrm{mg} /$ $\mathrm{dl}$; HDL-C $<40 \mathrm{mg} / \mathrm{dl}$ (men) or $<50 \mathrm{mg} / \mathrm{dl}$ (women); blood pressure $\geq 130 / 85 \mathrm{mmHg}$ or receiving treatment for previously diagnosed hypertension. FBS $\geq 100 \mathrm{mg} / \mathrm{dl}$ or use of medication to treat diabetes. [30].

Current smoking was defined as smoking cigarettes or water pipes at the study time. Physical activity level was assessed based on metabolic equivalent (MET) levels were ranged on a scale from sleep/rest to high-intensity physical activities. Participants were grouped into 2 groups as sedentary/low activity (inactive group) and active group, according to the MET values [28].

The following formulas were applied to calculate the anthro-metabolic indices [13, 19, 31-33]:

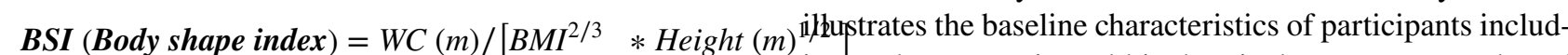

$\bullet$

BAI $($ Body Asiposity Index $)=\left[\right.$ hip circumference $(\mathrm{cm}) /\left(\right.$ height $\left.(m)^{1.5}\right]-18$

- LAP (Lipid Accumulation Production)

Men : $\quad[T G(\mathrm{mmol} / \mathrm{L}) *[W C(\mathrm{~cm})-65]$

Women : $[T G(\mathrm{mmol} / \mathrm{L})] *[\mathrm{WC}(\mathrm{cm})-58]$

- VAI(Viseral Adipiosity Index)
To assess the predictive capacity of the anthro-metabolic indices in identifying MetS, the receiver operating characteristic (ROC) curves were applied. Areas under the curves (AUCs) and 95\% confidence intervals (CIs) were calculated to compare the predictive value of the various indices in identify MetS. The cutoff point of each indicator was determined based on the maximum value of Youden's index [34].

Logistic regression analyses were performed to determine the associations between MetS and anthro-metabolic indices, odds ratios (ORs) with 95\% confidence intervals in crude and adjusted models were reported.

$P$ values $<0.05$ were considered as statistically significant. We used the Stata 14 software (StataCorp. 2015. Stata Statistical Software: Release 14. College Station, TX: StataCorp LP) to perform the statistical analyses.

\section{Results}

A total of 2426 subjects ( $48.1 \%$ men) with mean \pm SD age of $69.34 \pm 6.40$ years were included in the study. Table 1 ik kustrates the baseline characteristics of participants includ-
ing anthropometric and biochemical measurements based on sex and MetS category. According to ATP III criteria, $34.8 \%$ of men and $65.2 \%$ of women had MetS $(\mathrm{P}<0.001)$. Men and women with MetS had higher BMI, waist and hip circumferences than people without MetS $(\mathrm{P}<0.001)$. Also, people with Mets in both genders had higher weight and height compared to participants without MetS. There were

$$
\begin{gathered}
\text { Men : } \quad V A I=\left(\frac{W C(\mathrm{~cm})}{39.68+(1.88 * B M I)}\right) *\left(\frac{T G(\text { mmol } / l}{1.03}\right) *\left(\frac{1.31}{H D L(\mathrm{mmol} / \mathrm{l}}\right) \\
\text { Women }: V A I=\left(\frac{W C(\mathrm{~cm})}{36.58+(1.89 * B M I)}\right) *\left(\frac{T G(\mathrm{mmol} / \mathrm{l})}{0.81}\right) *\left(\frac{1.52}{H D L(\text { mmol } / \mathrm{l})}\right)
\end{gathered}
$$

BRI (Body Roundness Index $)=364.2-\left(365.5 * \sqrt{1-\left(\frac{\frac{W C}{2 \pi}}{0.5 * H e i g h t}\right)^{2}}\right.$

\section{Statistical methods}

Baseline characteristics of the participants were reported based on the MetS status in men and women separately. Continuously-distributed variables were described by reporting their mean \pm standard deviations and were compared using the independent t-test, Categorical data, explained by percentages, were tested by chi2 or Fisher's exact.
HDL-C between MetS (+) and MetS (-) in both genders $(P<0.001)$.

Table 2 presents the mean of anthro-metabolic indices according to have MetS in both genders. The mean of all anthro-metabolic indices were higher in MetS (+) than MetS $(-)$ in men and women $(P<0.001)$.

Table 3 shows the cut-off points of anthro-metabolic indices in predicting MetS with sensitivity, specificity, and AUC for gender category and total participants. 
Table 1 General characteristics of participants by having MetS in both genders

\begin{tabular}{|c|c|c|c|c|c|c|}
\hline \multirow[t]{2}{*}{ Variables } & \multicolumn{3}{|l|}{$\operatorname{Men}(n=1166)$} & \multicolumn{3}{|c|}{ Women $(n=1256)$} \\
\hline & $\begin{array}{l}\text { MetS (+) } \\
(n=454)\end{array}$ & $\begin{array}{l}\text { MetS (-) } \\
(n=712)\end{array}$ & $P$ value & $\begin{array}{l}\text { MetS (+) } \\
(n=849)\end{array}$ & $\begin{array}{l}\text { MetS (-) } \\
(n=407)\end{array}$ & $P$ value \\
\hline Age(Years) & $69.06 \pm 6.23$ & $69.85 \pm 6.56$ & 0.041 & $68.72 \pm 5.83$ & $70.08 \pm 7.25$ & $<0.001$ \\
\hline Education years & $7.09 \pm 5.04$ & $7.38 \pm 5.25$ & 0.339 & $3.17 \pm 3.93$ & $3.52 \pm 4.24$ & 0.160 \\
\hline Physical activity & $93(20.5)$ & $178(25.0)$ & 0.075 & $197(23.2)$ & $87(21.4)$ & 0.469 \\
\hline Current smoking & $92(20.3)$ & $180(25.3)$ & 0.048 & $147(17.3)$ & $84(20.7)$ & 0.152 \\
\hline Weight (Kg) & $78.13 \pm 11.65$ & $68.58 \pm 11.39$ & $<0.001$ & $69.15 \pm 12.24$ & $61.31 \pm 13.36$ & $<0.001$ \\
\hline Height $(\mathrm{Cm})$ & $166.49 \pm 6.31$ & $165.48 \pm 6.28$ & 0.008 & $152.54 \pm 5.84$ & $151.60 \pm 6.63$ & 0.011 \\
\hline $\mathrm{WC}(\mathrm{Cm})$ & $102.96 \pm 9.65$ & $93.34 \pm 10.54$ & $<0.001$ & $103.09 \pm 11.08$ & $94.27 \pm 13.26$ & $<0.001$ \\
\hline Hip circumference $(\mathrm{Cm})$ & $102.19 \pm 7.03$ & $97.51 \pm 7.52$ & $<0.001$ & $107.42 \pm 10.74$ & $101.72 \pm 11.21$ & $<0.001$ \\
\hline $\operatorname{BMI}\left(\mathrm{Kg} / \mathrm{m}^{2}\right)$ & $28.15 \pm 3.70$ & $25.02 \pm 3.73$ & $<0.001$ & $29.73 \pm 5.14$ & $26.58 \pm 5.12$ & $<0.001$ \\
\hline FBG (mg/dl) & $122.00 \pm 48.58$ & $93.47 \pm 29.00$ & $<0.001$ & $117.05 \pm 49.85$ & $88.36 \pm 19.71$ & $<0.001$ \\
\hline $\mathrm{TG}(\mathrm{mg} / \mathrm{dl})$ & $173.43 \pm 77.99$ & $102.74 \pm 42.61$ & $<0.001$ & $161.97 \pm 77.02$ & $97.73 \pm 29.31$ & $<0.001$ \\
\hline Cholesterol (mg/dl) & $174.13 \pm 43.69$ & $172.79 \pm 38.94$ & 0.587 & $188.23 \pm 47.83$ & $195.14 \pm 39.93$ & 0.012 \\
\hline HDL-C (mg/dl) & $37.50 \pm 8.51$ & $46.64 \pm 9.45$ & $<0.001$ & $44.80 \pm 9.81$ & $56.53 \pm 10.80$ & $<0.001$ \\
\hline LDL-C (mg/dl) & $102.40 \pm 36.85$ & $106.00 \pm 33.37$ & 0.085 & $111.33 \pm 41.35$ & $119.46 \pm 35.50$ & 0.001 \\
\hline HTN & $372(81.9)$ & $451(63.4)$ & $<0.001$ & $721(84.9)$ & $224(55.0)$ & $<0.001$ \\
\hline
\end{tabular}

Data are presented as mean \pm standard deviation or number(percent)

$M e t S$ Metabolic Syndrome, BMI body mass index, $W C$ waist circumference, $F B G$ fasting blood glucose, $H D L-C$ High Density LipoproteinCholesterol, $L D L-C$ Low Density Lipoprotein-Cholesterol, $T G$ triglycerides, HTN hypertension

Table 2 Characteristics of anthro-metabolic indices among studied population stratified by MetS

\begin{tabular}{|c|c|c|c|c|c|c|}
\hline \multirow[b]{2}{*}{ Variables } & \multicolumn{3}{|l|}{ Men } & \multicolumn{3}{|l|}{ Women } \\
\hline & $\operatorname{MetS}(+)$ & $\operatorname{MetS}(-)$ & $P$ value & $\operatorname{MetS}(+)$ & $\operatorname{MetS}(-)$ & $P$ value \\
\hline BSI & $0.0884 \pm 0.004$ & $0.0869 \pm 0.005$ & $<0.001$ & $0.896 \pm 0.006$ & $0.0883 \pm 0.006$ & 0.001 \\
\hline BAI & $29.66 \pm 3.80$ & $27.88 \pm 3.87$ & $<0.001$ & $39.17 \pm 6.62$ & $36.57 \pm 6.06$ & $<0.001$ \\
\hline BRI & $5.94 \pm 1.43$ & $4.73 \pm 1.31$ & $<0.001$ & $7.40 \pm 1.97$ & $6.09 \pm 2.02$ & $<0.001$ \\
\hline LAP & $73.07 \pm 36.07$ & $33.45 \pm 19.50$ & $<0.001$ & $82.37 \pm 44.08$ & $40.06 \pm 19.30$ & $<0.001$ \\
\hline Waist to hip ratio & $1.01 \pm 0.06$ & $0.96 \pm 0.11$ & $<0.001$ & $0.96 \pm 0.07$ & $0.93 \pm 0.07$ & $<0.001$ \\
\hline Waist to height ratio & $0.62 \pm 0.06$ & $0.56 \pm 0.06$ & $<0.001$ & $0.68 \pm 0.08$ & $0.62 \pm 0.09$ & $<0.001$ \\
\hline VAI & $3.06 \pm 1.73$ & $1.39 \pm 0.71$ & $<0.001$ & $3.60 \pm 2.46$ & $1.62 \pm 0.66$ & $<0.001$ \\
\hline
\end{tabular}

Data are presented as mean \pm standard deviation

MetS Metabolic syndrome, BSI body shape index, BAI body adiposity index, BRI body roundness index, $V A I$ visceral adiposity index
The optimal cutoff point for BSI was 0.088 (sensitivity $66.55 \%$, specificity $46.68 \%$ ) in women and 0.087 (sensitivity $66.30 \%$, specificity $49.16 \%$ ) in men, for BRI was 5.42 (sensitivity $63.44 \%$, specificity $72.61 \%$ ) in men and 5.35 (sensitivity $89.40 \%$, specificity $40.79 \%$ ) in women in prediction of MetS. Also, the optimal cutoff point for identifying Mets for VAI was 2.31 in women with $70.32 \%$ sensitivity and $87.71 \%$ specificity, and 1.88 in men with $77.97 \%$ sensitivity and $81.46 \%$ specificity. The optimal cutoff points for BAI and LAP were 26.89 (sensitivity $78.85 \%$, specificity $38.06 \%$ ) and 49.31 (sensitivity $74.00 \%$, specificity $83.71 \%$ ) in men, respectively and also 36.37 (sensitivity $65.37 \%$, specificity $52.58 \%$ ) and 52.39 (sensitivity $76.09 \%$, specificity $76.90 \%$ ) in women, respectively.

Among women, the Waist to height ratio and Waist to hip ratio cut points were 0.60 (sensitivity $87.87 \%$, specificity $41.28 \%$ ) and 0.92 (sensitivity $75.62 \%$, specificity $44.72 \%$ ) respectively, and 0.60 (sensitivity $61.89 \%$, specificity $73.46 \%$ ) and 0.97 (sensitivity $74.89 \%$, specificity $60.39 \%$ ), respectively in men.

Of the seven examined indices, the AUCs of VAI and LAP in both genders were higher than other anthro-metabolic indices. Also, among the general population, VAI and LAP had the greatest predictive power for MetS with AUC 
Table 3 Cut points, sensitivity, specificity, and area under curve of anthro-metabolic indices to identify metabolic syndrome among participants in the BEH Study

\begin{tabular}{|c|c|c|c|c|}
\hline Anthro-metabolic Indices & Cut-Points & Sensitivity $(95 \% \mathrm{CI})$ & Specificity $(95 \%$ CI $)$ & $\operatorname{AUC}(95 \% \mathrm{CI})$ \\
\hline \multicolumn{5}{|l|}{ Total } \\
\hline BSI & 0.089 & $52.34(49.59-55.08)$ & $63.45(60.55-66.28)$ & $0.60(0.58-0.62)$ \\
\hline BAI & 32.04 & $65.92(63.28-68.50)$ & $65.42(62.55-68.20)$ & $0.70(0.68-0.72)$ \\
\hline BRI & 5.72 & $73.06(70.56-75.46)$ & $68.10(65.28-70.82)$ & $0.76(0.74-0.78)$ \\
\hline LAP & 49.31 & $77.90(75.54-80.12)$ & 79.45(76.96-81.78) & $0.87(0.85-0.88)$ \\
\hline Waist to hip ratio & 0.98 & $50.04(47.29-52.79)$ & $70.24(67.47-72.91)$ & $0.63(0.61-0.65)$ \\
\hline Waist to height ratio & 0.61 & $74.29(71.03-76.64)$ & $66.85(64.00-69.60)$ & $0.76(0.74-0.78)$ \\
\hline VAI & 2.10 & $72.14(69.62-75.56)$ & $84.27(82.00-86.36)$ & $0.87(0.86-0.89)$ \\
\hline \multicolumn{5}{|l|}{ Men } \\
\hline BSI & 0.087 & $66.30(61.75-70.64)$ & $49.16(45.42-52.90)$ & $0.59(0.56-0.62)$ \\
\hline BAI & 26.89 & $78.85(74.81-82.52)$ & $38.06(34.48-41.74)$ & $0.62(0.59-0.65)$ \\
\hline BRI & 5.42 & $63.44(58.82-67.88)$ & $72.61(69.18-75.86)$ & $0.74(0.71-0.76)$ \\
\hline LAP & 49.31 & $74.00(69.72-77.99)$ & 83.71(80.79-86.35) & $0.87(0.85-0.89)$ \\
\hline Waist to hip ratio & 0.97 & $74.89(70.64-78.82)$ & $60.39(56.69-64.01)$ & $0.73(0.70-0.76)$ \\
\hline Waist to height ratio & 0.60 & $61.89(57.25-66.38)$ & $73.46(70.05-76.67)$ & $0.74(0.71-0.76)$ \\
\hline VAI & 1.88 & 77.97(73.88-81.70) & $81.46(78.41-84.25)$ & $0.86(0.84-0.88)$ \\
\hline \multicolumn{5}{|l|}{ Women } \\
\hline BSI & 0.088 & $66.55(63.26-69.72)$ & $46.68(41.75-51.66)$ & $0.56(0.53-0.60)$ \\
\hline BAI & 36.37 & $65.37(62.06-68.57)$ & $52.58(47.60-57.52)$ & $0.62(0.58-0.65)$ \\
\hline BRI & 5.35 & $89.40(87.13-91.39)$ & $40.79(35.97-45.74)$ & $0.68(0.65-0.72)$ \\
\hline LAP & 52.39 & $76.09(73.07-78.92)$ & $76.90(72.50-80.91)$ & $0.85(0.82-0.87)$ \\
\hline Waist to hip ratio & 0.92 & $75.62(72.59-78.47)$ & $44.72(39.82-49.69)$ & $0.64(0.61-0.67)$ \\
\hline Waist to height ratio & 0.60 & 87.87(85.48-89.99) & $41.28(36.45-46.23)$ & $0.68(0.65-0.72)$ \\
\hline VAI & 2.31 & $70.32(67.12-73.37)$ & $87.71(84.13-90.74)$ & $0.86(0.84-0.88)$ \\
\hline
\end{tabular}

$B S I$ body shape index, $B A I$ body adiposity index, $B R I$ body roundness index, $V A I$ visceral adiposity index
$0.87(0.86-0.89)$ and $0.87(0.85-0.88)$, respectively. The lowest AUC in total people was observed in BSI with the area under the curve of 0.60(0.58-0.62). (Table 3, Fig. 1).

The results of logistic regression of MetS and each of the anthro-metabolic indices, one at a time, were illustrated in Table 4. After adjusting for the demographic confounders, the highest odds ratio (OR) for MetS in the total population was observed in VAI and LAP, which were 16.63 (13.31-20.79) and $12.56(10.23-15.43)$ respectively. The lowest OR for MetS was 1.93(1.61-2.30) based on BSI. Since the interaction between sex and waist to height ratio in predicting the MetS was significant sex-specific ORs were calculated, the OR of waist to height ratio in women was higher than men [OR: 5.90(95\%CI: 4.37, 7.98) and 4.42(95\% CI: 3.42, 5.71) in women and men, respectively].

\section{Discussion}

Anthro-metabolic indices have been introduced as effective indicators to predict MetS in clinical setting [35]. However, differences in the inapplicability of the best predictive index from different countries and ethnic groups make it necessary to find an appropriate cut-off value for separate populations
$[35,36]$. In this study, more than half of the population had metabolic syndrome. We discovered that VAI and LAP were the strongest predictors of MetS among Iranian elderly aged $\geq 60$ years. Other anthropometric indices showed a weak sensitivity or specificity $(<70 \%)$ to identify MetS in elderly men and women. The results did not change after controlling for potential confounding factors.

Our reported prevalence of MetS was lower than that reported in Turkey [37] and Colombia [38]; however, the lower prevalence was reported in Brazil [39] and China [40]. Our findings are in line with previous nationwide studies with an alarming prevalence among populations more than 65 years, regardless of the defined criteria [41, 42]. Mets were estimated from $31.1 \%$ to $74 \%$ by using different criteria, including ATP III, IDF, AHA/NHLBI, and JIS [42, 43]. Such a wide variation could be attributed to the cut-off points used to define central obesity, which is affected by ethnicity-specific values [44].

VAI is a gender-specific mathematical model formulated based on both anthropometric (BMI and WC) and functional (TG, HDL-C) parameters [19]. Sufficient evidence suggests abdominal obesity as a principal risk factor for metabolic diseases such as diabetes mellitus and cardiovascular diseases $[45,46]$. Waist circumference is a main clinical index 

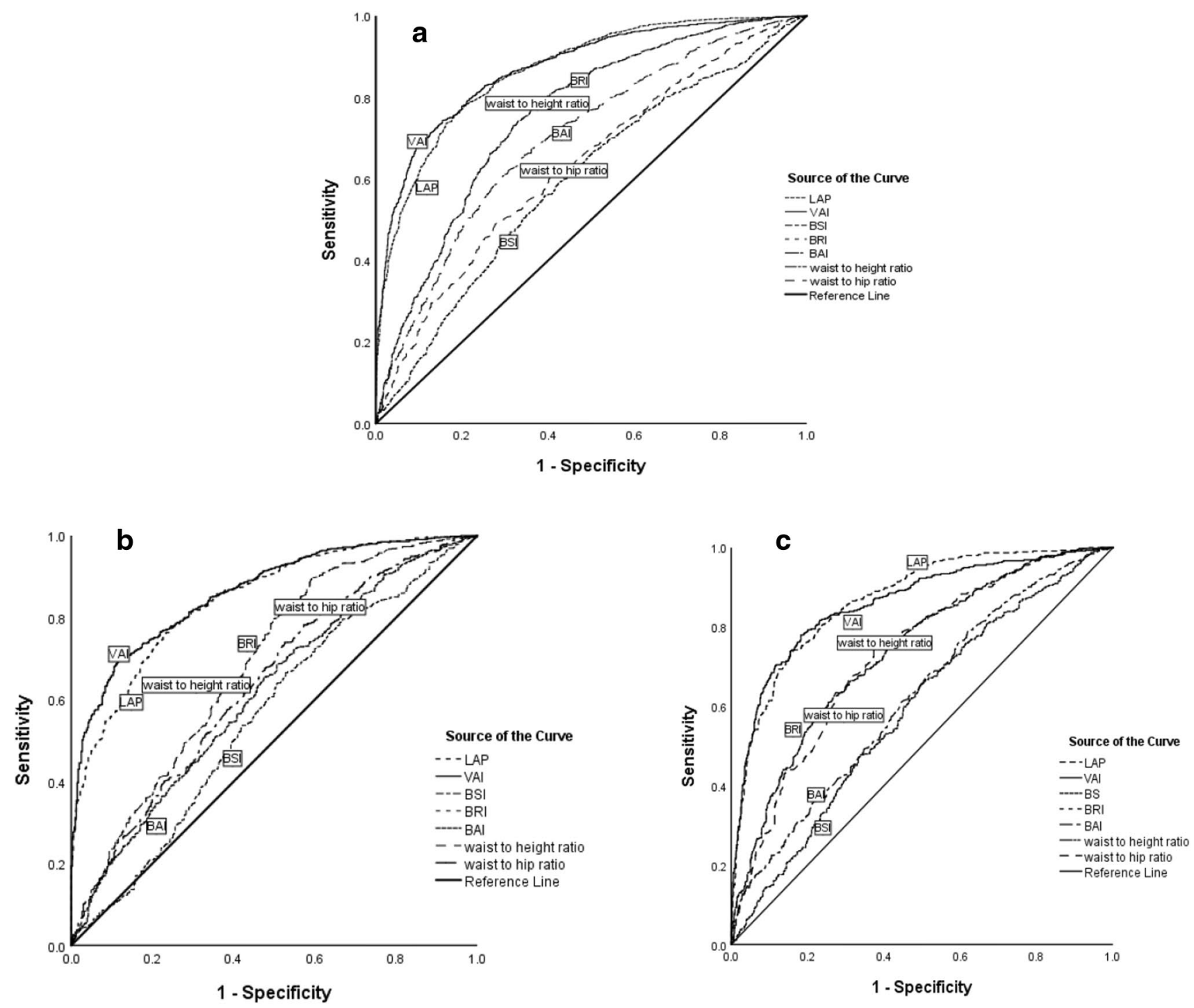

Fig. 1 Receiver-operating characteristic (ROC) analysis of anthro-metabolic indices versus vs. reference line for prediction metabolic syndrome in total (A), women $(\mathbf{B})$ and men $(\mathbf{C})$

Table 4 Logistic Regression of MetS on Cutoff Points of each anthrometabolic indices

\begin{tabular}{lll}
\hline Anthropometric Indices & Model-1 & Model-2 \\
\hline BSI & $1.85(1.57-2.18)$ & $1.93(1.61-2.30)$ \\
BAI & $1.78(1.51-2.11)$ & $1.83(1.54-2.18)$ \\
BRI & $6.48(5.40-7.77)$ & $5.91(4.90-7.13)$ \\
LAP & $13.24(10.89-16.11)$ & $12.56(10.23-15.43)$ \\
Waist to hip ratio & $3.71(3.12-4.40)$ & $3.50(2.93-4.17)$ \\
Waist to height ratio & $6.45(5.38-7.74)$ & $5.89(4.89-7.10)$ \\
VAI & $13.91(11.38-17.00)$ & $16.63(13.31-20.79)$ \\
\hline
\end{tabular}

Model 1: crude model, Model 2: adjusted for Age, sex, education, Physical activity, current smoking

$B S I$ body shape index, $B A I$ body adiposity index, $B R I$ body roundness index, $V A I$ visceral adiposity index to indirectly measure the increased visceral fat [47]. However, WC may not be useful for differentiating between subcutaneous and visceral fat mass [48]. The VAI has been reported independently associated with adipose tissue dysfunction and related cardio- and cerebrovascular events [19]. We found that VAI would have the best predictive capacity for MetS in an elderly population of Southern Iran. The same findings were reported in Mazandaran, a Northern province of Iran, with the related AUC of 0.85 to 0.902 [49]. VAI and WC and WHtR were also reported as the best predictors of MetS components among Peruvians aged 15 or older [50].

We present further findings on the predictive capacity of LAP in elderly people. In some populations, LAP was found to be a beneficial predictor of multiple health conditions, including CVDs [51] and chronic kidney diseases 
[52]. In middle-aged and older people of Korea, LAP could predict MetS and exhibited the greatest accuracy of diagnosis (AUC $=0.92$ ) [53]. In Japanese adults, this parameter was found to have good power in the prediction of both coronary artery disease and MetS [54]. Such a predicting ability of LAP was also documented in adults from China and older adults from Taiwan [18, 55]. Reflecting visceral adiposity level, LAP gives more advantages to predict MetS [56]. The integration of triglyceride in the LAP formula provides a practical tool to recognize a high amount of visceral fat in individuals [18].

Our study has some limitations. The results are restricted to healthy populations in Southern Iran aged 60 and over; therefore, these may not apply to other populations. Also, the absence of a uniform international classification for MetS limits the comparison of results to other studies. Further, calculation of modern anthropometric indices could involve measurement errors, which may bias the results; however, we emphasize that all data were collected preciously with independent trained personnel. Despite limitations, several strengths can be accounted for in the present work. First, it was a population-based study with a large number of elderly participants. The data are representative of a large sample of Iranian people and randomly selected from a cohort study which minimizes the selection bias. Moreover, several potential confounders were taken into account.

\section{Conclusions}

In conclusion, this study indicated that VAI and LAP are the most valuable indices among the considered anthro-metabolic indices to identify MetS among the elderly. Although, the VAI formula includes more defining variables of MetS and there is no big advantage for using VAI instead of ATP III criteria in terms of cost. While, LAP can be easily calculated through routine laboratory tests and simple anthropometric measurements, and therefore can be used as relevant assessment tools for MetS in clinical practice. However, the cost-benefit for using this index compared to the ATP III criteria need further studies.

Acknowledgments We would like to thank all the personnel of the Bushehr Elderly Health program and all the individuals who took part in the study.

Authors' contributions All authors read and approved the final paper.

\section{Declarations}

Conflict of interest The authors declare that they have no conflict interests.

\section{References}

1. Shin D, Kongpakpaisarn K, Bohra C. Trends in the prevalence of metabolic syndrome and its components in the United States 2007-2014. Int J Cardiol. 2018;259:216-9.

2. Rochlani Y, Pothineni NV, Kovelamudi S, Mehta JL. Metabolic syndrome: pathophysiology, management, and modulation by natural compounds. Ther Adv Cardiovasc Dis. 2017;11(8):215-25.

3. Khamseh ME, Ansari M, Malek M, Shafiee G, Baradaran H. Effects of a structured self-monitoring of blood glucose method on patient self-management behavior and metabolic outcomes in type 2 diabetes mellitus. J Diabetes Sci Technol. 2011;5(2):388-93.

4. Mazloomzadeh S, Khazaghi ZR, Mousavinasab N. The prevalence of metabolic syndrome in Iran: a systematic review and meta-analysis. Iran J Public Health. 2018;47(4):473.

5. Nikbakht H-A, Rezaianzadeh A, Seif M, Ghaem H. Prevalence of metabolic syndrome and its components among a populationbased study in south of Iran, PERSIAN Kharameh cohort study. Clin Epidemiol Glob Health. 2020;8(3):678-83.

6. Gadde KM, Martin CK, Berthoud H-R, Heymsfield SB. Obesity: pathophysiology and management. J Am Coll Cardiol. 2018;71(1):69-84.

7. Jayawardena R, Ranasinghe P, Ranathunga T, Mathangasinghe Y, Wasalathanththri S, Hills AP. Novel anthropometric parameters to define obesity and obesity-related disease in adults: a systematic review. Nutr Rev. 2020;78(6):498-513.

8. Prentice AM, Jebb SA. Beyond body mass index. Obes Rev. 2001;2(3):141-7.

9. Nuttall FQ. Body mass index: obesity, BMI, and health: a critical review. Nutr Today. 2015;50(3):117.

10. Ryan JM, Crowley VE, Hensey O, McGahey A, Gormley J. Waist circumference provides an indication of numerous cardiometabolic risk factors in adults with cerebral palsy. Arch Phys Med Rehabil. 2014;95(8):1540-6.

11. Gadekar T, Dudeja P, Basu I, Vashisht S, Mukherji S. Correlation of visceral body fat with waist-hip ratio, waist circumference and body mass index in healthy adults: a cross sectional study. Med J Armed Forces India. 2020;76(1):41-6.

12. Shao J, Yu L, Shen X, Li D, Wang K. Waist-to-height ratio, an optimal predictor for obesity and metabolic syndrome in Chinese adults. J Nutr Health Aging. 2010;14(9):782-5.

13. Krakauer NY, Krakauer JC. A new body shape index predicts mortality hazard independently of body mass index. PLoS One. 2012;7(7):e39504.

14. Stefanescu A, Revilla L, Lopez T, Sanchez SE, Williams MA, Gelaye B. Using a body shape index (ABSI) and body roundness index (BRI) to predict risk of metabolic syndrome in Peruvian adults. J Int Med Res. 2020;48(1):0300060519848854.

15. Haghighatdoost F, Sarrafzadegan N, Mohammadifard N, Asgary S, Boshtam M, Azadbakht L. Assessing body shape index as a risk predictor for cardiovascular diseases and metabolic syndrome among Iranian adults. Nutrition. 2014;30(6):636-44.

16. Rico-Martín S, Calderón-García JF, Sánchez-Rey P, FrancoAntonio C, Martínez Alvarez M, Sánchez Muñoz-Torrero JF. Effectiveness of body roundness index in predicting metabolic syndrome: a systematic review and meta-analysis. Obes Rev. 2020;21(7):e13023.

17. Taverna MJ, Martínez-Larrad MT, Frechtel GD, Serrano-Ríos M. Lipid accumulation product: a powerful marker of metabolic syndrome in healthy population. Eur J Endocrinol. 2011;164(4):559.

18. Chiang J-K, Koo M. Lipid accumulation product: a simple and accurate index for predicting metabolic syndrome in Taiwanese people aged 50 and over. BMC Cardiovasc Disord. 2012;12(1):1-6. 
19. Amato MC, Giordano C, Galia M, Criscimanna A, Vitabile S, Midiri M, et al. Visceral adiposity index: a reliable indicator of visceral fat function associated with cardiometabolic risk. Diabetes Care. 2010;33(4):920-2.

20. Bennasar-Veny M, Lopez-Gonzalez AA, Tauler P, Cespedes ML, Vicente-Herrero T, Yañez A, et al. Body adiposity index and cardiovascular health risk factors in Caucasians: a comparison with the body mass index and others. PLoS One. 2013;8(5):e63999.

21. Djibo DA, Araneta MRG, Kritz-Silverstein D, Barrett-Connor E, Wooten W. Body adiposity index as a risk factor for the metabolic syndrome in postmenopausal Caucasian, African American, and Filipina women. Diabetes Metab Syndr. 2015;9(2):108-13.

22. Motamed N, Razmjou S, Hemmasi G, Maadi M, Zamani F. Lipid accumulation product and metabolic syndrome: a population-based study in northern Iran, Amol. J Endocrinol Investig. 2016;39(4):375-82.

23. Rotter I, Rył A, Szylińska A, Pawlukowska W, Lubkowska A, Laszczyńska M. Lipid accumulation product (LAP) as an index of metabolic and hormonal disorders in aging men. Exp Clin Endocrinol Diabetes. 2017;125(03):176-82.

24. Goldani H, Adami FS, Antunes MT, Rosa LH, Fassina P, Grave MTQ, et al. Applicatility of the visceral adiposity index (VAI) in the prediction of the components of the metabolic syndrome in elderly. Nutricion hospitalaria. 2015;32(4):1609-15.

25. Liu P, Ma F, Lou H, Zhu Y. Body roundness index and body adiposity index: two new anthropometric indices to identify metabolic syndrome among Chinese postmenopausal women. Climacteric. 2016;19(5):433-9.

26. Heshmat R, Heidari M, Ejtahed HS, Motlagh ME, Mahdavi-Gorab A, Ziaodini $\mathrm{H}$, et al. Validity of a continuous metabolic syndrome score as an index for modeling metabolic syndrome in children and adolescents: the CASPIAN-V study. Diabetol Metab Syndr. 2017;9:89

27. Ostovar A, Nabipour I, Larijani B, Heshmat R, Darabi H, Vahdat $\mathrm{K}$, et al. Bushehr elderly health (BEH) Programme, phase I (cardiovascular system). BMJ Open. 2015;5(12):e009597.

28. Shafiee G, Ostovar A, Heshmat R, Darabi H, Sharifi F, Raeisi A, et al. Bushehr elderly health (BEH) programme: study protocol and design of musculoskeletal system and cognitive function (stage II). BMJ Open. 2017;7(8):e013606.

29. Aadahl M, Jorgensen T. Validation of a new self-report instrument for measuring physical activity. Med Sci Sports Exerc. 2003;35(7):1196-202

30. Ervin RB. Prevalence of metabolic syndrome among adults 20 years of age and over, by sex, age, race and ethnicity, and body mass index: United States, 2003-2006. Natl Health Stat Report. 2009;2009(13):1-7.

31. Bergman RN, Stefanovski D, Buchanan TA, Sumner AE, Reynolds JC, Sebring NG, et al. A better index of body adiposity. Obesity (Silver Spring). 2011;19(5):1083-9.

32. Kahn HS. The "lipid accumulation product" performs better than the body mass index for recognizing cardiovascular risk: a population-based comparison. BMC Cardiovasc Disord. 2005;5:26.

33. Thomas DM, Bredlau C, Bosy-Westphal A, Mueller M, Shen W, Gallagher D, et al. Relationships between body roundness with body fat and visceral adipose tissue emerging from a new geometrical model. Obesity (Silver Spring). 2013;21(11):2264-71.

34. Fluss R, Faraggi D, Reiser B. Estimation of the Youden index and its associated cutoff point. Biom J. 2005;47(4):458-72.

35. Wang H, Liu A, Zhao T, Gong X, Pang T, Zhou Y, et al. Comparison of anthropometric indices for predicting the risk of metabolic syndrome and its components in Chinese adults: a prospective, longitudinal study. BMJ Open. 2017;7(9):e016062.

36. Banik SD, Pacheco-Pantoja E, Lugo R, Gómez-de-Regil L, Aké RC, González RMM, et al. Evaluation of anthropometric indices and lipid parameters to predict metabolic syndrome among adults in Mexico. Diabetes Metab Syndr Obes. 2021;14:691.

37. Erem C, Hacıhasanoglu A, Deger O, Topbaş M, Hosver I, Ersoz $\mathrm{HO}$, et al. Prevalence of metabolic syndrome and associated risk factors among Turkish adults: Trabzon MetS study. Endoctrine. 2008;33(1):9-20.

38. Barranco-Ruiz Y, Villa-González E, Venegas-Sanabria LC, Chavarro-Carvajal DA, Cano-Gutiérrez CA, Izquierdo M, et al. Metabolic syndrome and its associated factors in older adults: a secondary analysis of SABE Colombia in 2015. Metab Syndr Relat Disord. 2020;18(8):389-98.

39. Saad MAN, Cardoso GP, de Andrade MW, Velarde LGC, da Cruz Filho RAJABDC. Prevalence of metabolic syndrome in elderly and agreement among four diagnostic criteria. Arq Bras Cardiol. 2014;102(3):263.

40. Yan H, Zhang M, Zhang X, Xia Y, Shen T, Zhao Z, et al. Study of epidemiological characteristics of metabolic syndrome and influencing factors in elderly people in China. Zhonghua Liu Xing Bing Xue Za Zhi. 2019;40(3):284-9.

41. Tabatabaei-Malazy O, Saeedi Moghaddam S, Rezaei N, Sheidaei A, Hajipour MJ, Mahmoudi N, et al. A nationwide study of metabolic syndrome prevalence in Iran; a comparative analysis of six definitions. PLoS One. 2021;16(3):e0241926.

42. Kozan O, Oguz A, Abaci A, Erol C, Ongen Z, Temizhan A, et al. Prevalence of the metabolic syndrome among Turkish adults. Eur J Clin Nutr. 2007;61(4):548-53.

43. Hosseinpanah F, Asghari G, Barzin M, Golkashani HA, Azizi F. Prognostic impact of different definitions of metabolic syndrome in predicting cardiovascular events in a cohort of non-diabetic Tehranian adults. Int J Cardiol. 2013;168(1):369-74.

44. Azizi F, Hadaegh F, Khalili D, Esteghamati A, Hosseinpanah F, Delavari A, et al. Appropriate definition of metabolic syndrome among Iranian adults: report of the Iranian National Committee of Obesity. Arch Iran Med. 2010;13(5):426-8.

45. Bao Y, Lu J, Wang C, Wang C, Yang M, Li H, Zhang X, et al. Optimal waist circumference cutoffs for abdominal obesity in Chinese. Atherosclerosis. 2008;201(2):378-84.

46. Ritchie S, Connell JJN. The link between abdominal obesity, metabolic syndrome and cardiovascular disease. Nutr Metab Cardiovasc Dis. 2007;17(4):319-26.

47. Mathieu P, Pibarot P, Larose E, Poirier P, Marette A, Després J-PJTIJOB, et al. Visceral obesity and the heart. Int J Biochem Cell Biol. 2008;40(5):821-36.

48. Pouliot M-C, Després J-P, Lemieux S, Moorjani S, Bouchard C, Tremblay A, et al. Waist circumference and abdominal sagittal diameter: best simple anthropometric indexes of abdominal visceral adipose tissue accumulation and related cardiovascular risk in men and women. Am J Cardiol. 1994;73(7):460-8.

49. Motamed N, Khonsari M, Rabiee B, Ajdarkosh H, Hemasi G, Sohrabi M, et al. Discriminatory ability of visceral adiposity index (VAI) in diagnosis of metabolic syndrome: a population based study. Exp Clin Endocrinol Diabetes. 2017;125(03):202-7.

50. Knowles K, Paiva L, Sanchez S, Revilla L, Lopez T, Yasuda M, et al. Waist circumference, body mass index, and other measures of adiposity in predicting cardiovascular disease risk factors among Peruvian adults. Int J Hypertens. 2011;2011:931402.

51. Hosseinpanah F, Barzin M, Mirbolouk M, Abtahi H, Cheraghi L, Azizi F. Lipid accumulation product and incident cardiovascular events in a normal weight population: Tehran lipid and glucose study. Eur J Prev Cardiol. 2016;23(2):187-93.

52. Biyik Z, Guney IJERMPS. Lipid accumulation product and visceral adiposity index: two new indices to predict metabolic syndrome in chronic kidney disease. Eur Rev Med Pharmacol Sci. 2019;23(5):2167-73.

53. Shin K-A, Kim YJJD. Usefulness of surrogate markers of body fat distribution for predicting metabolic syndrome in middle-aged 
and older korean populations. Diabetes Metab Syndr Obes. 2019;12:2251.

54. Wakabayashi I, Daimon TJCCA. The "cardiometabolic index" as a new marker determined by adiposity and blood lipids for discrimination of diabetes mellitus. Clin Chim Acta. 2015;438:274-8.

55. Zhou C, Zhan L, Yuan J, Tong X, Peng Y, Zha Y, et al. Comparison of visceral, general and central obesity indices in the prediction of metabolic syndrome in maintenance hemodialysis patients. Eat Weight Disord. 2020;25(3):727-34.
56. Kahn HS. The "lipid accumulation product" performs better than the body mass index for recognizing cardiovascular risk: a population-based comparison. BMC Cardiovasc Disord. 2005;5:26.

Publisher's note Springer Nature remains neutral with regard to jurisdictional claims in published maps and institutional affiliations.

\section{Authors and Affiliations}

\section{Neda Rabiei ${ }^{1} \cdot$ Ramin Heshmat $^{1}$ - Safoora Gharibzadeh ${ }^{2}$. Afshin Ostovar ${ }^{3} \cdot$ Vahid Maleki $^{4,5} \cdot$ Mehdi Sadeghian $^{6}$. Saba Maleki Birjandi ${ }^{1} \cdot$ Iraj Nabipour $^{7} \cdot$ Gita Shafiee $^{1} \cdot$ Bagher Larijani $^{1,8}$}

1 Chronic Diseases Research Center, Endocrinology and Metabolism Population Sciences Institute, Tehran University of Medical Sciences, Tehran, Iran

2 Department of Epidemiology and Biostatistics, Pasteur Institute of Iran, Tehran, Iran

3 Osteoporosis Research Center, Endocrinology and Metabolism Clinical Sciences Institute, Tehran University of Medical Sciences, Tehran, Iran

4 Clinical Cancer Research Center, Milad General Hospital, Tehran, Iran
5 Knee and Sport Medicine Research Center, Milad Hospital, Tehran, Iran

6 Shafa Nuroscience Research Center, Khatam Alanbia Hospital, Tehran, Iran

7 The Persian Gulf Tropical Medicine Research Center, Bushehr University of Medical Sciences, Bushehr, Iran

8 Endocrinology and Metabolism Research Center, Endocrinology and Metabolism Clinical Sciences Institute, Tehran University of Medical Sciences, Tehran, Iran 